\title{
Homozygous Machado Joseph Disease: A Case Report and Review of Literature
}

\author{
Liudmila Lysenko, Raji P. Grewal, Wei Ma, Leema Reddy Peddareddygari
}

Can. J. Neurol. Sci. 2010; 37: 521-523

The spinocerebellar ataxias (SCAs) are a clinically and genetically heterogeneous group of neurodegenerative disorders caused by cytosine-adenine-guanine $(\mathrm{CAG})$ trinucleotide repeat expansions. Machado Joseph Disease (MJD) or SCA-3 was originally described in the Portuguese Azores islands and currently it is the most common autosomal dominant SCA worldwide. It is caused by CAG repeat expansion in the exon 10 of the MJD gene which codes for the ataxin-3 protein and maps to chromosome14q24.3-q31. The number of CAG repeats in normal individual ranges from 12 to 40 while affected individuals carry 51 to $86 \mathrm{CAG}$ repeats in the disease producing allele. ${ }^{1}$

Machado Joseph Disease is an autosomal dominant disorder resulting from presence of a disease causing CAG repeat expansion in only one allele. Homozygous cases, where the disease causing CAG repeat expansion is present in both alleles of the gene, of any autosomal dominant disease are rare; however, they can occur in regions where consanguineous marriages are common. There have been ten cases of genetically confirmed homozygous MJD described in the literature (Table), one case of Azorean origin, one case of Brazilian origin, two cases of Japanese origin and six patients of Jewish descent from a small isolated region in Yemen. Consanguinity was reported in four of these cases; the six cases in Yemenite individuals were anonymized and therefore the exact family relationships were unreported..$^{2-6}$ In addition, two siblings of Azorean origin with early onset and rapid progression of MJD were reported. They were not genetically confirmed but presumed to be homozygous as both of their parents were affected with MJD, one of the children died eight years after the onset of symptoms. ${ }^{7}$ In homozygous MJD cases, the disease course had a wide range of age at onset ( 4 - 43 years old) with more pronounced extra pyramidal signs and pyramidal changes. The disease appears to be especially severe in the pediatric population. After normal development, these children had regression in motor skills, bulbar symptoms (difficulty swallowing, dysarthria), extrapyramidal changes (dystonia, bradykinesia and tremor), upper motor neuron signs and ataxia. Five years after onset the affected individuals became nonambulatory and were bedridden. Two patients with disease onset at the age of 16 years and 28 years presented with the development of spasticity, dysphagia, dysarthria, nystagmus and severe generalized dystonia and became nonambulatory within four years..$^{3,4}$ The latest onset of homozygous MJD described was 43-years-old and the patient presented with rapid eye movement behavior disorder followed by ataxia, bulbar changes, mild spasticity and psychiatric symptoms. ${ }^{6}$ None of these cases described exhibited sensory changes.
We report a patient with homozygous MJD presenting with spastic paraperesis.

\section{Case Report}

We present a 33-year-old patient (IV-1) of Portuguese/ Brazilian descent with onset of muscle cramps, twitching in the calves and spastic gait disturbance for about four years prior to evaluation. These symptoms had been slowly progressive since onset. There were no ocular or bulbar complaints, weakness or sensory symptoms. The past medical history was unremarkable. Family history disclosed that the parents are first cousins and that both the father (III-2) and the mother (III-3) became symptomatic at the age of 40 years. In addition, the paternal grandparent (II-2) and parent's cousin (III-1) also had similar symptoms with onset around 40 years-of-age. (Figure). By history all the affected members had symptoms of clumsiness and gait imbalance. However these family members live in Brazil and were not available for a neurological examination.

The patient's neurological exam revealed a normal mental status, normal cranial nerve and sensory examinations. The extraocular movements were intact and there was no nystagmus. Speech and swallowing were preserved. Full strength was noted with spastic muscle tone in both upper and lower extremities; fasciculations were observed in the tongue and muscles of both upper and lower limbs. The muscle stretch reflexes were increased and plantars were extensor bilaterally. Mild difficulty with tandem gait was observed. No limb ataxia and no extrapyramidal findings were noted.

The patient's metabolic panel including B12, folate, thyroidstimulating hormone, rapid plasma reagin and aldolase were normal. The creatine kinase levels were elevated (978 units/L, normal range in males is $38-174$ units/L). Precontrast magnetic resonance imaging (MRI) of the brain was performed in the sagittal plane using $\mathrm{T} 1$ weighting, in the axial plane using T1, T2 and CSF suppressed T2 weighting and in the coronal plane using T2 weighted recall imaging. The MRI showed ventricles of normal size, contour and configuration. The MRI did not reveal any evidence of cerebellar atrophy, intra-axial masses or any

\footnotetext{
From the New Jersey Neuroscience Institute at JFK Medical Center, Edison, New Jersey, U.S.A.

Received December 7, 2009. Final Revisions Submitted February 2, 2010. Correspondence to: Leema Reddy Peddareddygari, Laboratory of Neurogenetics, New Jersey Neuroscience Institute/JFK Medical Center, 65 James Street, Edison, New Jersey, 08820, U.S.A.
} 
Table: Clinical features of previously reported individuals with homozygous MJD

\begin{tabular}{|c|c|c|c|c|}
\hline Reference & $\begin{array}{l}\text { Patient's } \\
\text { origin }\end{array}$ & $\begin{array}{l}\text { Age of } \\
\text { onset }\end{array}$ & $\begin{array}{l}\text { Number of } \\
\text { CAG repeats }\end{array}$ & Clinical features \\
\hline Fukutake et al. 2002 & Japanese & 43 years & $60 / 60$ & $\begin{array}{l}\text { Rapid eye movement behavior disorder and psychiatric } \\
\text { symptoms (hallucinations, delusions), slow saccades, impaired } \\
\text { pursuit, horizontal gaze evoked nystagmus, alternating skew } \\
\text { deviation, dysarthria, up going plantars bilaterally, dysmetria in } \\
\text { all four limbs, ataxic gait }\end{array}$ \\
\hline Sobue et al. 1996 & Japanese & 28 years & $67 / 67$ & $\begin{array}{l}\text { Bulging eyes, facial grimacing, fasciculations in facial muscles, } \\
\text { dysarthria, dystonic posture, spastic muscle tone in lower } \\
\text { extremities, hyperreflexia, bilaterally upgoing plantars, } \\
\text { dysmetria, ataxic gait }\end{array}$ \\
\hline \multirow[t]{6}{*}{ Lerer et al. 1996} & $\begin{array}{l}\text { Yemenite } \\
\text { Jewish }\end{array}$ & 29 years & $64 / 70$ & $\begin{array}{l}\text { Facial grimacing, dysarthria, lower motor neuron disease, gait } \\
\text { ataxia }\end{array}$ \\
\hline & Yemenite & 37 years & $65 / 66$ & Lower motor neuron disease, gait ataxia \\
\hline & Jewish & 25 years & $67 / 68$ & \\
\hline & Yemenite & 17 years & $65 / 69$ & Ophthalmoplegia, facial grimacing, dysarthria, lower motor \\
\hline & Jewish & 30 years & $67 / 68$ & neuron disease, gait ataxia \\
\hline & & 36 years & $65 / 69$ & \\
\hline Carvalho et al. 2008 & Brazilian & 4 years & $67 / 72$ & $\begin{array}{l}\text { Regression of motor skills, } \\
\text { bulging eyes, nystagmus, facial hypomimia with open mouth } \\
\text { and drooling, dysarthria, dysphagia, dystonia in tongue, face, } \\
\text { upper extremities and trunk, bradykinesia, spastic tone in the } \\
\text { lower extremities, hyperreflexia, bilaterally upgoing plantars, } \\
\text { intention tremor, gait ataxia }\end{array}$ \\
\hline Lang et al. 1994 & $\begin{array}{l}\text { Portuguese } \\
\text { /Azorean }\end{array}$ & 16 years & $\begin{array}{l}\text { Confirmed } \\
\text { but unknown } \\
\text { number of } \\
\text { repeats }\end{array}$ & $\begin{array}{l}\text { Up gaze limitations, gaze evoked horizontal nystagmus, } \\
\text { dysarthria, generalized dystonia, postural instability, } \\
\text { hyperreflexia }\end{array}$ \\
\hline \multirow[t]{2}{*}{ Coutinho et al. 1982} & Azorean & 8 years & $\begin{array}{l}\text { Not } \\
\text { confirmed } \\
\text { genetically }\end{array}$ & $\begin{array}{l}\text { Scoliosis, pes cavus, bulging eyes, } \\
\text { limitation of upward gaze and convergence, facial } \\
\text { fasciculations, dysphagia, dysarthria, generalized dystonia, } \\
\text { cogwheel rigidity in both upper extremities, spastic tone in both } \\
\text { lower extremities, hyperreflexia, upgoing plantars bilaterally, } \\
\text { dysmetria more pronounced in left extremities, gait ataxia } \\
\text { patient passed away at } 15 \text {-years-old }\end{array}$ \\
\hline & Azorean & 7 years & $\begin{array}{l}\text { Not } \\
\text { confirmed } \\
\text { genetically }\end{array}$ & Gait ataxia, no other data available \\
\hline
\end{tabular}

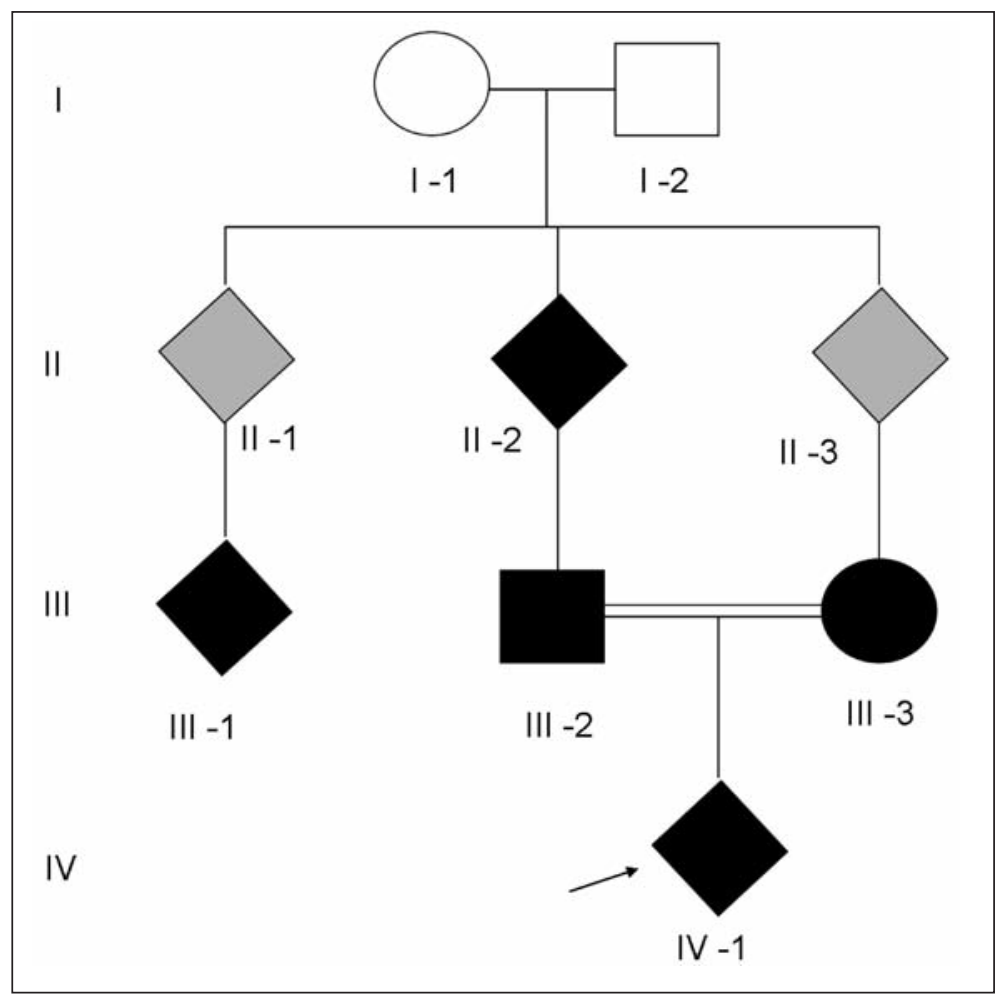

Figure: Pedigree of the patient's family. The squares indicate males, circle females, diamonds indicated gender unknown; dark fill indicates affected individuals and gray is probably affected. Some of the individuals are represented with diamonds to anonymize the pedigree. 
region of abnormal signal. An electrophysiological study showed no evidence of generalized sensory-motor or sensory neuropathy. Needle electromyography revealed fasciculations in many muscles sampled from upper and lower extremities. Motor unit potential morphology and duration was normal except for the presence of fasciculations. No abnormal spontaneous activity was observed. Taking into account the Portuguese/Brazilian ancestry and a family history suggestive of an autosomal dominant progressive neurodegenerative disorder, MachadoJoseph Disease (SCA3) was suspected and genetic testing was performed by a commercial laboratory. This analysis confirmed that this patient had homozygous MJD with expansions of 63 and 60 repeats.

\section{DiscuSSION}

The "CAG" codon codes for the amino acid glutamine and the presence of expanded CAG repeats results in a polyglutamine expansion in the resulting protein. The polyglutamine rich ataxin-3 protein is neurotoxic for susceptible areas of the brain including cerebellum (mostly dentate nucleus and cerebellar peduncles), brainstem (mostly oculomotor nuclei and vestibular nuclei), basal ganglia (mostly subthalamic nucleus, globus pallidus and striatum), spinal cord (mostly spinocerebellar tracts, Clarke's column nucleus, dorsal columns and anterior horn cells) and may also affect the peripheral nerves.

In the U.S.A., MJD/SCA3 represents $21 \%$ of familial ataxia and is most prevalent in families of Portuguese and Brazilian descent. The number of CAG repeats is inversely correlated with the age of onset and severity of disease and has been clinically characterized into five types. Long CAG repeats are associated with early onset ( 5 to 30 years), a rapidly progressive course and clinical features of dystonia, spasticity, facial and lingual fasciculations and exophthalmos (type I). Patients with intermediate $\mathrm{CAG}$ expansion repeats disease manifest the disease at approximately age 36 years and present with moderately progressive ataxia (type II). The later onset of disease (40 years) is associated with cerebellar signs, peripheral neuropathy and ophthalmoplegia (type III). The fewest CAG repeats results in late onset (38-47 years), slow progression and features of Parkinsonism, fasciculations, peripheral neuropathy and distal atrophy (type IV). A new subtype reported in Japanese families, SCA3/MJD patients show marked spastic paraparesis with or without cerebellar ataxia (subtype V). (http:// neuromuscular.wustl.edu/ataxia/domatax.html\#mjd).

This is the 11th case of genetically confirmed homozygous MJD reported. In homozygous individuals, compared with the heterozygous patients, the age of onset is typically earlier, more severe and the degree of disease progression is more rapid. Our patient had relatively earlier age at onset of symptoms compared to the other affected members in the family. However, in comparison to the other homozygous patients, the age of onset was relatively later. Further more this presentation with spastic paraparesis without extra pyramidal features or significant ataxia (subtype V) is unique. This patient expands the clinical heterogeneity of homozygous MJD patients.

\section{REFERENCES}

1. Sudarsky L, Coutinho P. Machado-Joseph disease. Clin Neurosci. 1995; 3(1):17-22.

2. Carvalho DR, La Rocque-Ferreira A, Rizzo IM, Imamura EU, Speck-Martins CE. Homozygosity enhances severity in spinocerebellar ataxia type 3. Pediatr Neurol. 2008 Apr; 38(4): 296-9.

3. Lang AE, Rogaeva EA, Tsuda T, Hutterer J, St George-Hyslop P. Homozygous inheritance of the Machado-Joseph disease gene. Ann Neurol. 1994 Sep; 36(3):443-7.

4. Sobue G, Doyu M, Nakao N, Shimada N, Mitsuma T, Maruyama H, et al. Homozygosity for Machado-Joseph disease gene enhances phenotypic severity. J Neurol Neurosurg Psychiatry. 1996 Mar; 60(3):354-6.

5. Lerer I, Merims D, Abeliovich D, Zlotogora J, Gadoth N. MachadoJoseph disease: correlation between the clinical features, the CAG repeat length and homozygosity for the mutation. Eur $\mathrm{J}$ Hum Genet. 1996; 4(1):3-7.

6. Fukutake T, Shinotoh H, Nishino H, Ichikawa Y, Goto J, Kanazawa I, et al. Homozygous Machado-Joseph disease presenting as REM sleep behaviour disorder and prominent psychiatric symptoms. Eur J Neurol. 2002 Jan; 9(1):97-100.

7. Coutinho P, Guimarães A, Scaravilli F. The pathology of MachadoJoseph disease. Report of a possible homozygous case. Acta Neuropathol. 1982; 58(1):48-54. 